\title{
Draft Code of Ethics
}

This is the recomended revised Journalist Code of Ethics drafted by Australia's Media, Arts and Entertainment Alliance (MEAA):

JOURNALISTS describe society to itself. They seek truth. They convey information, ideas and opinions, a privileged role. They search, disclose, record, question, entertain, suggest and remember. They inform citizens and animate democracy. They give a practical form to freedom of expression. Many journalists work in private enterprise, but all have these public responsibilities. They scrutinise power, but also exercise it, and should be accountable. Accountability engenders trust. Without trust, journalists do not fulfil their public responsibilities. MEAA members engaged in journal. ism commit themselves to:

Honesty

Fairness

Independence

Respect for the rights of others.

In consultation with colleagues, they will apply the following standards.

1. Report and interpret honestly, striving for accuracy, fairness and disclosure of all essential facts. Do not suppress relevant available facts, nor give distorting emphasis.

2. Make efforts to give the subject of any damaging report opportunity to comment, preferably in that same report.

3. Urge the fair correction of errors.

4. Use fair and honest means to obtain material. Avoid misrepresentation and use of concealed equipment or surveillance devices.

5. Pictures and sound should be true and accurate. Any manipulation likely to mislead should be disclosed.

6. Plagiarism is stealing. Always attribute fairly.

7. Only quote directly what is actually said or written. Otherwise paraphrase. Meaning and context should be accurately reflected.

8. Disclose any direct or indirect payment made for interviews, pictures or information.

9. Do not allow personal beliefs or commitments to undermine accuracy, fairness and independence. Where relevant, disclose.

10. Do not allow payment, gift or other advantage to undermine accuracy, fairness and independence. Where relevant, disclose. 
11. Do not improperly use a journalistic position for personal gain.

12. Guard against advertising or commercial considerations improperly influencing journalism. Where it occurs, disclose.

13. Accept the right to privacy of every person. Public figures' privacy may be reduced by their public role. Relatives and friends of those in the public eye retain their own right to privacy.

14. At times of grief or trauma always act with sensitivity and discretion. Never harass. Never exploit a person's vulnerability or ignorance of media practice. Interview only with informed consent.

15. Do not place unnecessary emphasis on personal characteristics including race,ethnicity, nationality, gender, age, sexual orientation, family relationships, religious belief or physical or mental disability.

16. Never knowingly endanger the life or safety of a person without informed consent.

17. Exercise particular care for the welfare of children in reports involving them.

18. Respect every person's right to a fair trial.

19. Aim to attribute as precisely as possible all information to its source. When a source seeks anonymity, do not agree without first considering the source's motive and any alternative attributable sources. Keep confidences given in good faith.

20. Educate yourself about ethics and help to enforce this code.

Basic values sometimes clash and ethics requires conscientious decision-making in context. Only substantial considerations of public interest or substantial harm to people allows any standard to be overridden.

Current Australian Journalists' Code of Ethics: (A model for the current PNG Journalists' Association code).

Members of the AJA are reminded that enforcing of the code of ethics is an important duty. Respect for truth and the public's right to information are over-riding principles for all journalists. In pursuance of these principles journalists commit themselves to ethical and professional standards. All members of the AJA engaged in gathering, transmitting, disseminating and commenting on news and information shall observe the following Code of Ethics in their professional activities. They acknowledge the jurisdiction of their professional colleagues in AJA judiciary committees to adjudicate on issues connected with this Code.

1. They shall report and interpret the news with scrupulous honesty by striving to disclose all essential facts and by not suppressing relevant 
available facts or distorting by wrong or improper emphasis.

2 . They shall not place unnecessary emphasis on gender, race, sexual preference, religious belief, marital status or physical or mental disability.

3. In all circumstances they shall respect all confidences received in the course of their calling.

4. They shall not allow personal interests to influence them in their professional duties.

5. They shall not allow their professional duties to be influenced by any consideration, gift or advantage offered and, where appropriate, shall disclose any such offer.

6. They shall not allow advertising or commercial considerations to influence them in their professional duties.

7. They shall use fair and honest means to obtain news, pictures, film, tapes and documents.

8. They shall identify themselves and their employers before obtaining any interview for publication or broadcast.

9. They shall respect private grief and personal privacy and shall have the right to resist compulsion to intrude on them.

10. They shall do their utmost to correct any published or broadcast information found to be harmfully inaccurate.

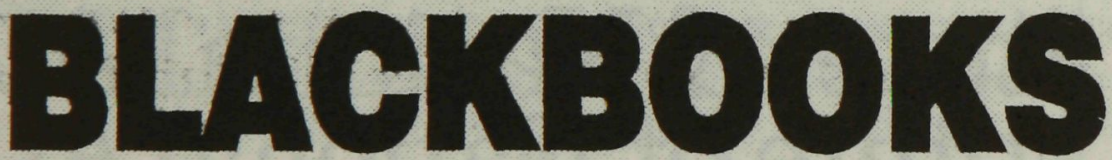

BlackBooks stocks the best collection of books on Aboriginal topics from bush tucker to kids stories, from massacres to tent embassy, from music to biographies. Also t-shirts, cassettes, CDs, posters, flags, craft work. Specialist in educational books. 1996 Catalogue avallable now.

Drop around or phone us with your queries.

11 Mansfield Street, Glebe NSW 2037

Phone: (02) 96602396 Fax: (02) 96601924 